\title{
The stitched textile technology and its emotional consideration property in fashion design
}

\author{
Yushan Zou; Desheng Zhang \\ (College of textiles and garments, Southwest University, Chongqing China, 400715)
}

\begin{abstract}
In the modern world, fashion designers have kept exploring more skills on fabric in the field of product development. The stitched textile technology attracted increasing attention due to its characteristics of emotion expressing, easy-sculpting and color-matching. The present paper introduced this textile redesign skill and a fashion artist named Gwen Hedley who did an excellent job in stitched textile application. Additionally, a vivid case of this technique adopted by us in womenswear design was shared in this paper. We conclude that stitched textile can help to enhance the uniformity of whole collection and emotion consideration in fashion design.
\end{abstract}

Keywords: stitched textile, womenswear, fashion designing, emotional consideration

\section{Introduction}

With the public aesthetic promotion, common clothing can not satisfy people's needs. In the high industrialized and mechanized society, fashion products were shown in a same reutilization. Many designers lost their own personalities in this field. While textile design comes out and by combine the technique with modeling, the inspiration may reveal better. This trend guides designers to a new field of thinking. At the same time, the public identify encourage the development of fabric redesign. How to discover and create the unique style of cloth as well as the unique brand of culture is what fashion designer should thinking about. Albers (2000) claimed that hand making in the treatment of fabric appearance and the epidermis has great influence in fashion design. By stitching, textured fabric would well decorate design.

In the field of product development, fashion designers start to explore more on fabric. As Hedley (2010) agreed that line has great versatility, which is a basic element in fashion design; it could be used to create texture, mark and form. Stitched textiles combines fabric painting and printing, applied fabrics and hand and machine stitchery. I have paid great attention to the stitch artist named Gwen Hedley. She is an English textile artist who is strong recognized in textile. She can use stitching well on fabric. What she did is fabrics redo by using the techniques of stitching and hand sewing and most inspired for textured nature.

\section{The technology of stitched textile and its properties}

2.1 The technology and emotional expression of stitched textile

In textile arts, stitching is a basic element of sewing, embroidery and crochets no matter by hand or machine. It can be classified into running stitch, cross-stitch, chain stitch and so on. It is the most convenient way to do textile redesign. On the other hand, color or pattern design and fabric design have a common region, which is the texture or surface shape. That material effect would double the function effectively.

McQuaid (2005) claimed that technical textile is some of the most creative and newest examples of design nowadays. It is not only requiring aesthetic and decoration, but also visually arresting textile. The technical textile and its application represent unique. It needs artists, designers and engineers extraordinary amount of research and experiments. Sarah and Marie 
(2007) said, making use of recent technology innovation, traditional methods can be upgrading and renewed while craft and manufacture can come together to create unique and special artwork.

The reasons why I choose Gwen Hedley as my case study are not only because what her research is about stitching textile but also the works inspired from natural beauty as well. She got many techniques to make different fibrous surfaces. And the book named Drawn to Stitch which she wrote contained great sources of inspiration. There are many books found to speak of the technical of stitching, but this book teaches the readers not only how to stitch, but also guide learners start from the inspiration. It showed her whole design process stepby-step, visually introducing from inspiration to the final work. She shared the starting points, then by using different methods to get the creative ideas or special emotion consideration. Each piece of her art work is accompanied by the original design reference. In addition, what she putted forward is closed to nature. Hedley (2010) said, "As a designer-maker, your drawings are made for your own purposes as working documents and visual references." The idea on fabric is translated from designer's original thoughts which always company with some featured emotional considerations.

\subsection{The redesign process using stitching technology by Gwen Hedley}

Gwen Hedley's works are currently in two separate but related strands. One is marks and lines on the basis of pebbles and rocks-bold continuous raised ridged bands, scatterings of dots and dashes and so on. She was interested in exploring these things and then drawing, painting and stitching them. She enjoys the rhythmic stitching process, because the different line may influence the surface quality of fabrics. The other one is focusing on the surface of small discarded or washed up items, such as wood, metal, fabrics, bones and so on. They own the marks of disintegration and elemental change, which witness a mysterious history. She believes the erosion and transformations contain a certain beauty of their own.

What I appreciate for her thoughts is that seemingly normal objects can be beautiful and meaningful. Gwen
Hedley is seeking to do a visual dairy to express the beauty and emotion. The first step is drawing, which helps to close observation of the subject matter and understand its characteristics well. Then she would draw marks and colors when observation and writes notes. The last step is stitching. She thought that it is drawing with thread. She recommended a wide variety of easily obtained tools, such as sticks, twigs, cotton buds and blender. Those are normal things in our daily life, through these tools, the work should have a special feeling that closed to life. In addition, she introduced several drawing, coloring media and supplementary art materials. In this book, she used different materials like cartridge, newspaper, used teabags as the backgrounds.

Take "A creative Journey" which Gwen Hedley made by the year of 2007 as an example. At first, she took the picture of a metal plate embedded in a painted wall (Fig. 1). She selected the color from the eroded and rust metal, which are white, turquoise, rust and burgundy. What she focused on is the plenty of tonal variation, interesting out lined shapes and the soft irregular edges. Then the next step she did is drawing and design. She drew with a stick and ink. Hedley (2007) stated that on the one hand, this is freer in her approached; on the other hand, it is hardly for her to get too fiddly by using a sharpened kebab stick to drawing. At the same time, she went back to the photo, she adjusted the range of color and changes of tone within each color. The next step was stitching on fabric according former researching. The last step was soft the edged of color, the final cloth completed was shown in Fig. 2.

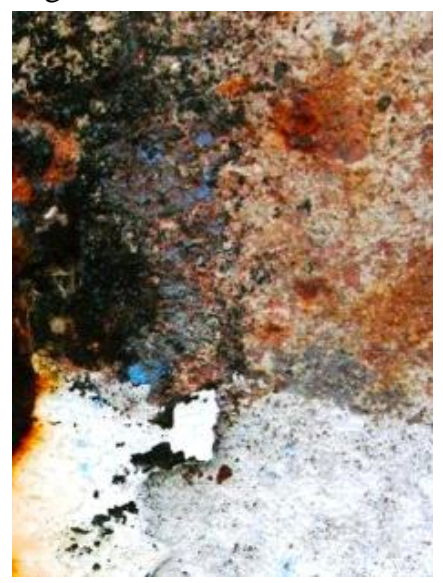

Fig.1 A metal plate. (Photo by Hedley, 2007) 


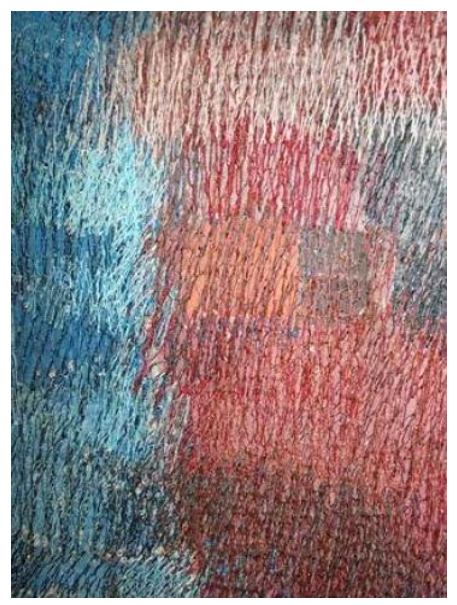

Fig.2 Final finished stitching piece. (Photo by Hedley 2007)

As Hedley (2007) said, when free machining in this way, I consider my machine as a drawing tool, using the needle to work freely, changing directions and colors in the same way as with pencils. At this stage, I refer back to the artwork, looking again at those final surface pencil marks, using them as a guide for the top layer of stitching (Gwen Hedley 2007).

\section{Practice of stitching technique applied in emotional fashion design}

\subsection{An applied case of stitching technique in womenswear design}

From the view of our points after plenty of thinking about stitching techniques, by which, the fabric redesigned has several characteristics as follows: Firstly, the fabric will harden after stitching. It is easier to do sculpt, so it appeared to be better applied in some special parts (Fig. 3). Secondly, the pattern that is abstracted and I can choose the color freely in order to match color. It will help to enhance the uniformity of whole collection. The last but very important is that the stitched fabric always appear to be of some special visual and tactual feelings which well suited for emotional expression.

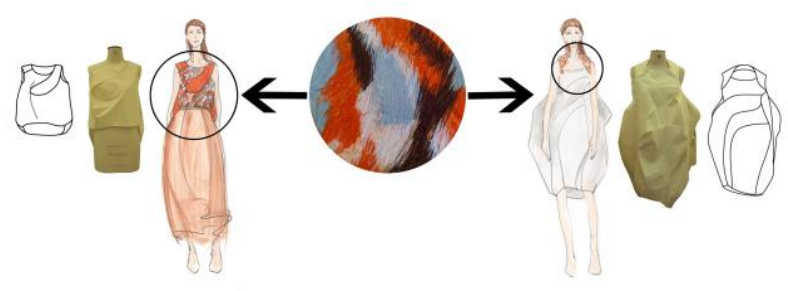

Fig. 3 Application of stitching fabric in womenswear design
As to me, I would like to use a combination of techniques in my stitched textile pictures. I designed several motifs. Stitching on fabric could push these motifs combined together to make my own unique pieces, with out any limits. I used different pieces of fabric and embellishing the details. I trended to enrich the textured surface, and the inspirations came from natural works, light, ancient relics and aging walls.

My research focused on the concept of time. The collection is inspired from a book named 8 Minutes. It is a picture collection of aging things, such as mottled walls, erosion stones and rusts. At the first page of the book, it is said, light is life, even if it's luminosity in the deepest ocean trench. If one minute is ten years then 8 minutes is a lifetime. The concept of time I defined is related light, so I collected some pictures about light at first (Fig. 4).

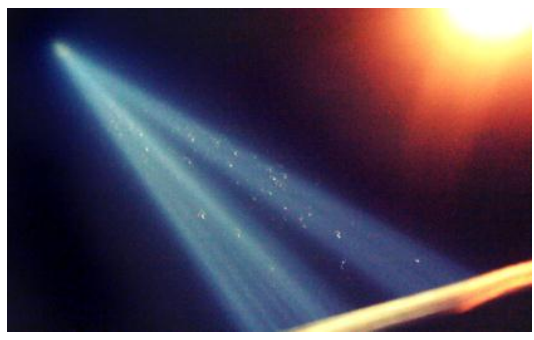

Fig.4 Memorial Lights Trap Thousands of Birds

(Photo by Brandon Keim, 2010)

The colors of orange, dark brown, grey and white are selected from the picture as the main color in the work. Then I follow Gwen Hedley's step to draw the shape by colored mark pen (Fig. 5). And then I sew on a linen fabric according to the picture I draw (Fig. 6). Actually, my research here is a little bit different from that of Gwen Hedley. The difference is about the materials. From the view of a fashion designer, I prefer more practical and wearable fabric. In addition, I will combine two different kinds of fabric such as yarn with jersey or yarn with linen. The combination may be another way to do fabric redesign. Under a light yarn, fabric show the feeling of obscurity and stylish. 


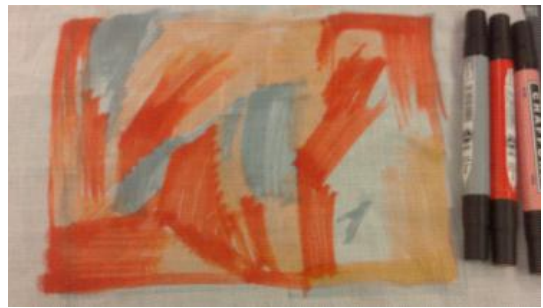

Fig. 5 Mark pen drawing

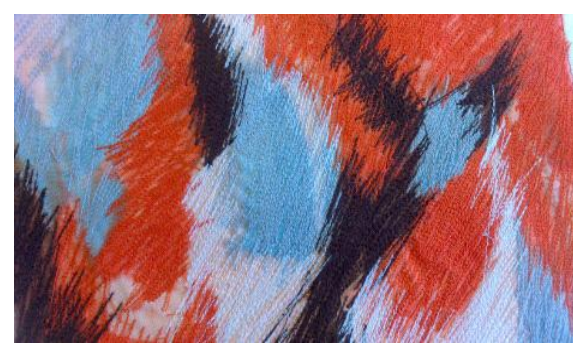

Fig.6 Stitching work

\subsection{The relationship of stitching between textile design}

\section{and fashion design}

Textile design plays an important role in fashion design, it helps designers express the ideas in a novel way. Thames et al (2007) hold the opinion that most majorities of fashion designers are doing design with manufacture of new materials. Thames et al (2007:127) stated that 'Yohji Yamamoto's main interests are material and form and their symbiotic relationship'. Yohji Yamamoto insists the importance of touching sense direct inspired him for his collections. He also works with numerous fabrics. Sometimes designers design fabrics for their collection, sometimes designers design collection begins with the textile. Many normal silhouettes under a designed fabric would like to show unmoral feelings. Thames et al (2007) suggested simple silhouettes and designs displayed the fabrics rather than complex cutting technology. All in all, the choice of textile would influence the eventual outlook and the message the design communicate.

Drawn to the aesthetic possibilities, the artists whose work in stitching arts like Gwen Hedley experimented with stitching on materials. As a fiber artist, she tried to transform traditional stitches into fiber art, she also encouraged others start from the inspirations. In this sense such embroidery is highly personal recognized and it decides the value of a garment. According to Sarah et al (2007), the clothing design point trend to the physical, the sensuality of touch and aging, a new dimension that seeps into fashion particular world.

\section{Conclusion}

With the development of Fashion design, fashion designers began to explore on fabric. Fashion cutting and modeling becomes fade out, on one hand most people prefer brief cutting and casual cloth. On the other hand, people would tired with similar cloth. So the innovative of fabric surface may add more value on cloth, meanwhile the style of the cloth will stand out.

People's aesthetic psychology was changed by the change of society development and lifestyle. Fashion designer should catch the fashion trend and design with various decorations.

After studying the case study of stitched textile, I would like to explore line's potential in embroidery. Creating lines is not limited to just printing techniques, as well as making fibrous surface. The fabric redesign is becoming a new task in fashion design. Sarah et al (2007) suggested designers had been rethinking traditional stitched textiles. A hand-stitched fabric replaced the traditional linen, to set embroidery in a different context. It is essential for a fashion designer know well of textile design, because it is not only a good way to promote design skills, but also to translate raw ideas or express emotions.

\section{References}

[1]. Albers, A. (2000) Constructing textiles. in Textile reader ed. by Hemmings, J. London: Berg Publishers, 387-390

[2]. Eckert, C. and Stacey, M. (2000) 'Sources of inspiration: a language of design' [online] available from <www.cse.dmu.ac.uk/ mstacey/pubs/sourcelang/soi-lod.doc> [10 April 2013].

[3]. Hemmings, J. (2012) The Textile Reader. London: Berg Publisher.

[4]. Hedley, G. (2004) Surfaces for Stitch: Plastics, Films and Fabrics, London: Batsford Ltd.

[5]. Hedley, G. (2007) Inspired Stitch: A Creative Journey-- Design and Stitch from Photographs 
from<http://www.workshopontheweb.com/july2001 /gwen.pdf> [27 April 2013].

[6]. Hedley, G. (2010) Drawn to Stitch: Line, Drawing, and Mark-Making in Textile Art, London: Batsford Ltd.

[7]. McQuaid, M. (2005) 'Stronger, faster, lighter, safer, and smarter'. in Textile reader ed. by Hemmings, J. London: Berg Publishers, 401-408

[8]. Stokes, T. (2002) 8 Minutes, London: Weproductions.

[9]. Sarah, E. and Marie, O. (2007) Techno textiles 2: Revolutionary Fabrics for fashion and design. London: Thames \& Hudson Ltd.

[10]. Sarah, E. and Marie, O. (1998) Techno textiles: Revolutionary Fabrics for fashion and design. London: Thames \& Hudson Ltd.

[11]. Thames and Hudson, (2011) The Fashion designer's textile directory: the creative use of fabrics in design, London: Thames and Hudson Ltd.

[12]. Fig.1 Gwen Hedley A metal plate 2007, source: Tate online http://www.workshopontheweb.com/july2001/gwen. pdf (accessed 27 April 2013)

[13]. Fig. 2 Gwen Hedley Final finished stitching piece 2007, Tate online

[14]. http://www.workshopontheweb.com/july2001/gwen. pdf (accessed 27 April 2013)

[15]. Fig. 3 Yushan Zou Application of stitching fabric in womenswear design, documenting Yushan Zou archive May 5th 2013, author's own image

[16]. Fig. 4 Brandon Keim 9/11 Memorial Lights Trap Thousands of Birds 2010, source: Tate online http://www.wired.com/wiredscience/2010/09/tribute -in-light-birds/ (accessed 7 April 2013)

[17]. Fig. 5 Yushan Zou Mark pen drawing, documenting Yushan Zou archive May 1st 2013, author's own image

[18]. Fig. 6 Yushan Zou Stitching work, documenting Yushan Zou archive May 2nd 2013, author's own image 